\title{
Pattern of LH and testosterone secretion of adult male fallow deer (Dama dama) during the transition into the breeding season
}

\author{
G. W. Asher and A. J. Peterson \\ Ruakura Agricultural Centre, Ministry of Agriculture and Fisheries, Private Bag, Hamilton, \\ New Zealand
}

\begin{abstract}
Summary. Pituitary secretion of LH and testicular secretion of testosterone were investigated during the transitional period from the non-breeding to breeding season of mature male fallow deer exhibiting either normal transitional patterns or shortened transitional patterns in response to summer melatonin treatment. Melatonin implants were administered to 4 bucks for a 150-day period starting 130 days after the winter solstice. Four contemporary bucks served as controls. Melatonin treatment advanced rutting activity, testis development and neck muscle hypertrophy by $6-8$ weeks. Profiles of plasma $\mathrm{LH}$ and testosterone, based on a 30-min sampling frequency over $24 \mathrm{~h}$, were obtained from 3 treated and 3 control bucks on 4 occasions over the period spanning the transition into the breeding season. In control bucks, $\mathrm{LH}$ and testosterone pulse frequency were low (0-2 pulses/24h) in January and increased (5-7 pulses $/ 24 \mathrm{~h}$ ) in February. By March and April (pre-rut and rut periods respectively) there was a two-fold increase in basal plasma $\mathrm{LH}$ concentrations, a decline in LH pulse frequency $(0-1 \mathrm{pulse} / 24 \mathrm{~h})$ and episodic surges in plasma testosterone concentrations. Melatonin treatment resulted in a shift in hormone profiles, with highly pulsatile patterns of LH and testosterone secretion ( 7 pulses $/ 24 \mathrm{~h}$ ) occurring earlier in January. The subsequent post-rut profiles of treated bucks were characterized by lower basal plasma $\mathrm{LH}$ concentrations, and reduced frequency and amplitude of plasma testosterone surges.
\end{abstract}

Keywords: fallow deer; reproduction; melatonin; LH; testosterone; testis

\section{Introduction}

Fallow deer (Dama dama) exhibit a highly seasonal pattern of reproduction, with the rut occurring in autumn and births occurring in summer (Chapman \& Chapman, 1975). This pattern is mediated primarily by photoperiod, as demonstrated by artificial manipulation of light:dark ratios (Schnare \& Fischer, 1987) or by strategic administration of exogenous melatonin (Asher et al., 1987, 1988). Studies on LH and testosterone secretion in adult entire and castrated fallow bucks demonstrated a number of endocrine events that serve to highlight the seasonal nature of reproduction in this species (Asher et al., 1989). Of particular interest in entire bucks is the temporal relationship between the pituitary gland and the testes during the transition from testicular quiescence in early summer to maximal spermatogenic and androgenic activity in autumn. This period was characterized by an increase in LH pulse frequency in late summer, leading to the pulsatile secretion of testosterone. However, the dynamic interaction between $\mathrm{LH}$ and testosterone secretion appeared to change during the rut period, with episodic secretion of testosterone being seemingly independent of any pulsatile secretion of LH (Asher et al., 1989). The 12-h sampling duration in the study was not adequate to show circadian patterns of hormone secretion. 
The present study aimed to investigate the diurnal pattern of $\mathrm{LH}$ and testosterone secretion during the transition from the non-breeding to breeding seasons of mature fallow deer bucks exhibiting either normal transitional patterns or shortened transitional patterns in response to summer melatonin treatment.

\section{Materials and Methods}

Animals and management. Eight polled entire bucks (7 years old), were grazed outdoors on ryegrass-white clover pasture at the Ruakura Agricultural Centre $\left(37^{\circ} 46^{\prime} \mathrm{S}, 175^{\circ} 20^{\prime} \mathrm{E}\right)$ for the duration of the trial period between November 1987 and November 1988. They were maintained as a bachelor group with other entire male fallow deer except during the period from February to May when they were run individually with groups of does for mating.

Trial protocol. Of the 8 entire bucks, 4 received single melatonin implants (Regulin [Batch Gr 7802/a]; Regulin Ltd, Melbourne, Victoria, Australia) on 4 November, 30 November, 30 December, 29 January and 29 February. Implants, each containing $18 \mathrm{mg}$ melatonin, were inserted subcutaneously at the base of the ear (Asher et al., 1988). The remaining 4 bucks received no implants and served as controls.

The bucks were mustered into the yards at 2-week intervals from 4 November 1987 to 17 November 1988 and liveweight, neck girth and testis diameter were recorded, as described by Asher et al. (1987). On 4 occasions after administration of the first implants (13 January, 10 February, 16 March and 21 April) 3 melatonin-treated bucks and 3 control bucks were mustered into the yards and blood sampled at 30 -min intervals for $24 \mathrm{~h}$. Samples $(5 \mathrm{ml})$ were withdrawn from the left external jugular vein via indwelling catheters (Intracath 3122; Deseret Company, Sandy, UT, USA) inserted $1 \mathrm{~h}$ before the start of sampling (09:00 h NZST). The bucks, which were well habituated to the handling procedures, were kept indoors under natural lighting and repeatedly restrained in a cradle device for sampling (Asher et al., 1989). Water and meadow hay were provided ad libitum. Blood samples were centrifuged within 30 min of collection and the plasma stored at $-10^{\circ} \mathrm{C}$ until assayed.

Hormone radioimmunoassays. Plasma LH concentrations were determined in duplicate using a heterologous radioimmunoassay procedure described for ovine plasma by Scaramuzzi et al. (1970). The entire assay has been validated previously for fallow deer plasma (Asher et al., 1986). The LH antibody, raised in a rabbit against NIHLH-SI1, was used in the assay at a final dilution of 1:200 000 . Cross-reactivity with other proteins has been described previously (Kelly et al., 1982; Asher et al., 1986). The inter-assay coefficients of variation, calculated from determinations of ovine control samples, were $11.6 \%$ for low (mean $=1.9 \mathrm{ng} / \mathrm{ml}), 15.2 \%$ for medium $(3.6 \mathrm{ng} / \mathrm{ml})$ and $7 \cdot 4 \%$ for high $(6.1 \mathrm{ng} / \mathrm{ml})$ samples. The intra-assay coefficient of variation was $3.6 \%$. The sensitivity of the standard curve was $0.03 \mathrm{ng} \mathrm{NIH}-\mathrm{LH}-\mathrm{S} 11$ per tube $(0 \cdot 30 \mathrm{ng} / \mathrm{ml})$.

Plasma testosterone concentrations were determined in duplicate using a direct radioimmunoassay based on a modified method of Peterson $e t$ al. (1978) and described by Asher $e t$ al. (1989). Serial dilutions of entire-buck plasma containing high concentrations of immunoreactive testosterone gave inhibition curves parallel to those generated for testosterone in buffer and charcoal-treated plasma from a castrated buck. The mean ( \pm s.e.m.) recovery of testosterone added to charcoal-treated plasma from a castrated buck ( 10 determinations) was $107.2 \pm 3.7 \%$ at $1.5 \mathrm{ng} / \mathrm{ml}$ $(5 \cdot 2 \mathrm{nmol} / \mathrm{l}), 109 \cdot 0 \pm 2 \cdot 2 \%$ at $3.0 \mathrm{ng} / \mathrm{ml}(10 \cdot 4 \mathrm{nmol} / \mathrm{l}), 94 \cdot 3 \pm 3.7 \%$ at $6.0 \mathrm{ng} / \mathrm{ml}(20 \cdot 8 \mathrm{nmol} / \mathrm{l})$ and $97 \cdot 0 \pm 6 \cdot 2 \%$ at $12.0 \mathrm{ng} / \mathrm{ml}(41.6 \mathrm{nmol} / \mathrm{l})$. The inter-assay coefficients of variation, calculated from determinations of low (mean $=2.6 \mathrm{nmol} / \mathrm{l})$, medium $(12.5 \mathrm{nmol} / \mathrm{l})$ and high $(28 \cdot 2 \mathrm{nmol} / \mathrm{l})$ control samples were $17 \cdot 1 \%, 9.8 \%$ and $7.5 \%$ respectively. The intra-assay coefficients of variation of the same control samples were $12 \cdot 3 \%, 3 \cdot 6 \%$ and $3.8 \%$ respectively. The sensitivity of the standard curve was $5 \mathrm{pg}(0 \cdot 17 \mathrm{nmol} / \mathrm{l})$.

Statistical analyses. LH and testosterone profiles were analysed separately for each buck at each sampling session using the PULSAR pulse identification routine (Merriam \& Wachter, 1982). Pulse analyses were carried out for 48 points. Inputs for PULSAR included intra-assay standard deviation and the smoothing time was set at $360 \mathrm{~min}$ for LH and $180 \mathrm{~min}$ for testosterone. A cut-off value of 2.7 standard deviation units was used for peak splitting. Temporal trends between $\mathrm{LH}$ and testosterone during testosterone surges were analysed by analysis of variance.

\section{Results}

The melatonin implantation regimen had pronounced effects on the annual pattern of liveweight, neck girth and testicular diameter changes in the bucks (Fig. 1). The treated bucks exhibited an earlier decline in mean liveweight associated with rutting activity, and an earlier increase in mean neck girth and testis diameter. On the basis of observed rutting activity of treated and control bucks (in the presence of melatonin-treated and untreated does), melatonin treatment advanced seasonal reproductive activity by $6-8$ weeks. 


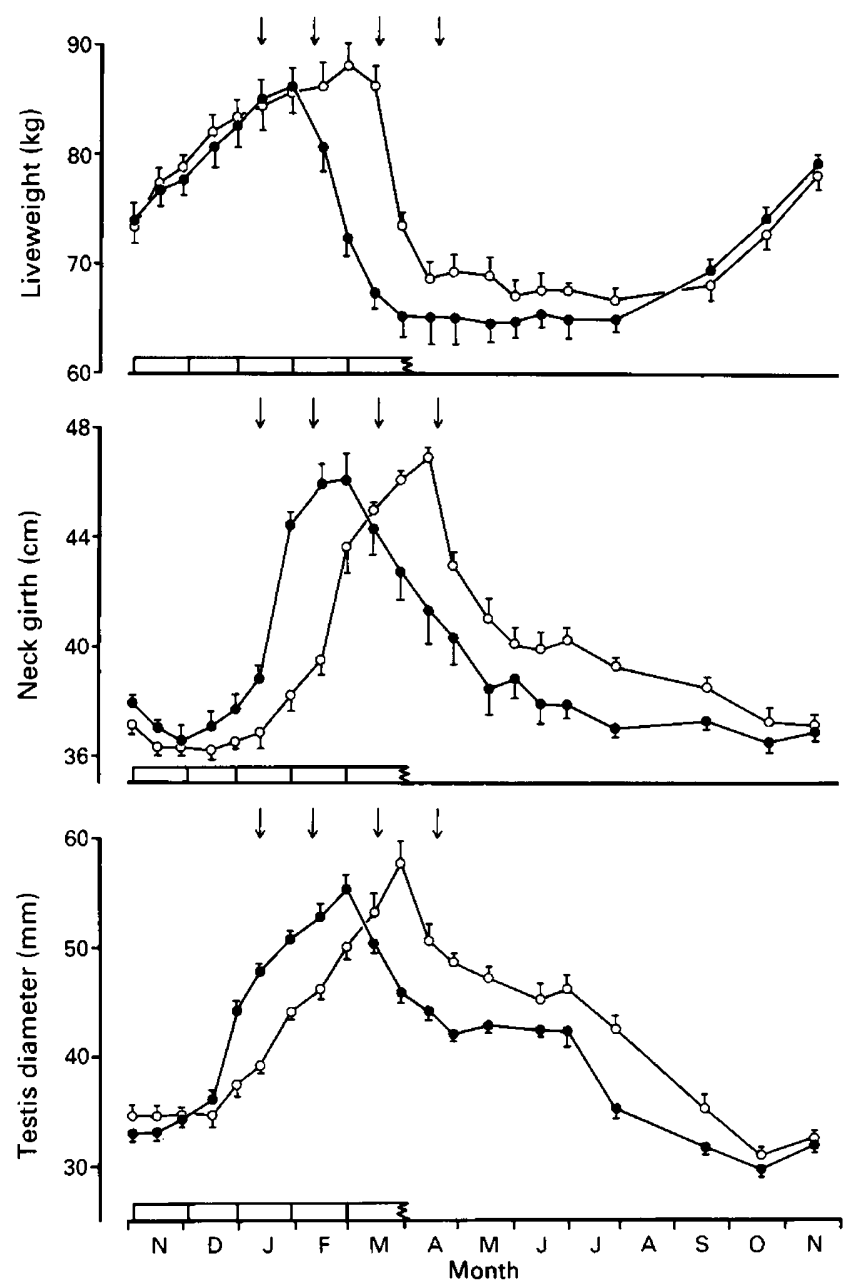

Fig. 1. Seasonal profiles of mean ( \pm s.e.m.) liveweight, neck girth and testis diameter of the 4 melatonin-treated $(O)$ and 4 control $(O)$ entire bucks. Horizontal bars represent the period of implantation and arrows indicate the dates of intensive blood sampling.

The 24-h profiles of plasma $\mathrm{LH}$ and testosterone concentrations of treated and control bucks (Fig. 2) show marked differences in the seasonal secretory pattern. The onset of the pulsatile release of LH and testosterone was advanced by melatonin treatment. In January there were few LH pulses (i.e. 0-2 pulses $/ 24 \mathrm{~h}$ ) in the control bucks and no apparent influence of these pulses on low basal testosterone concentrations $(<5 \mathrm{nmol} / 1)$. However, in February there was not only a marked increase in the frequency of LH release ( $5-7$ pulses $/ 24 \mathrm{~h}$ ) but also an increase in testosterone secretion, with an apparent 30 -min lag between the secretory peaks of the two hormones. The subsequent plasma profiles in March and April, the immediate pre-rut and rut periods, respectively, were characterized by decreasing basal concentrations of $\mathrm{LH}$, decreased frequency and amplitude of $\mathrm{LH}$ pulses and massive surges (4-8-h duration) in testosterone concentrations which occurred at a frequency of 2 per $24 \mathrm{~h}$ and were only occasionally associated with LH pulses.

In the melatonin-treated bucks the highest frequency of LH pulses, that were also associated temporally with testosterone pulses, occurred in January rather than in February. Furthermore, increases in basal plasma LH concentrations and the occurrence of plasma testosterone surges were evident in the February profile (i.e. the period representing the time of rutting activity in treated 


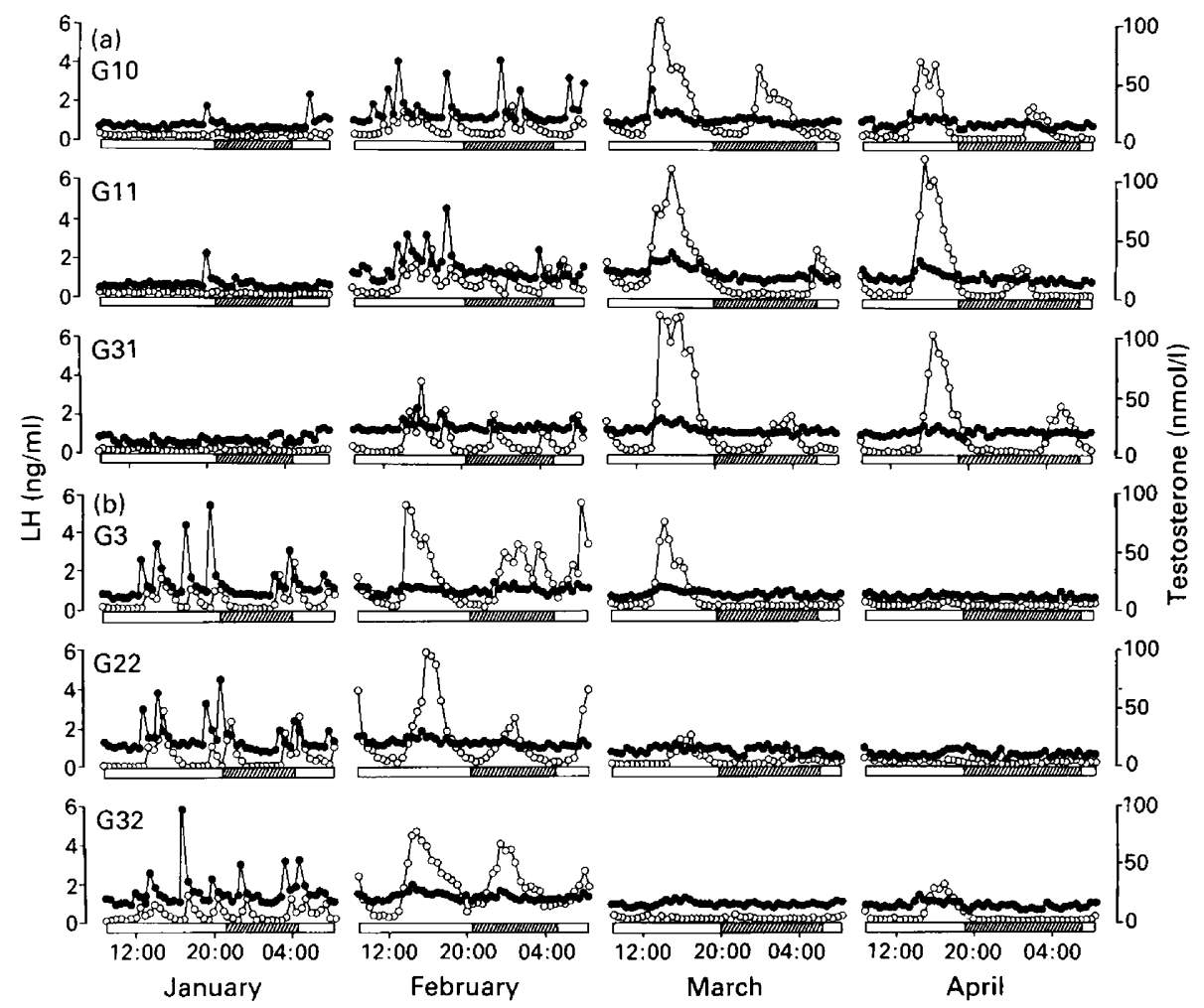

Fig. 2. Profiles over $24 \mathrm{~h}$ of plasma LH (O) and testosterone $(O)$ concentrations of 3 control (a) and 3 melatonin-treated (b) entire bucks during the transition period from the non-breeding to breeding seasons. The shaded portion of the abscissa axis indicates night time.

bucks) although the testosterone surges were more frequent ( 3 per $24 \mathrm{~h}$ ) than in March and April profiles of the control bucks. The March and April profiles of the treated bucks (i.e. representing their post-rut period) were characterized by a reduction in basal LH concentration, an almost complete absence of $\mathrm{LH}$ pulses and a marked reduction in episodes of testosterone secretion.

Further analysis of the pre-rut (March) and rut (April) plasma testosterone surges exhibited by the control bucks (Fig. 3) shows that for afternoon (12:00-20:00 h) surges there was a concomitant increase in mean plasma LH concentrations for the duration of the surge, whereby mean concentrations increased from 1.1 to $1.5 \mathrm{ng} / \mathrm{ml}(P<0.05)$. However, this was not the case for the lower amplitude morning (02:00-06:00 h) surges, for which no significant increases in mean plasma $\mathbf{L H}$ concentrations were observed $(P>0 \cdot 1)$.

\section{Discussion}

Several studies have shown that strategically administered exogenous melatonin shifts the seasonal breeding pattern of fallow deer (Asher et al., 1987, 1988). The present study on entire fallow bucks demonstrates that this shift is at least partly affected by an alteration in the pituitary secretion of LH. A major component of this alteration appears to be an increase in LH pulsatility 1 month earlier than in control bucks. This supports the hypothesis that melatonin, either endogenous or exogenous, has a regulatory influence on hypothalamic $\mathrm{GnRH}$ release (i.e. pulse generator; Karsch et al., 1988). How sustained release of melatonin from subcutaneous implants mediates its effects has yet to be elucidated (Lincoln \& Ebling, 1985). The natural melatonin secretory pattern in fallow 


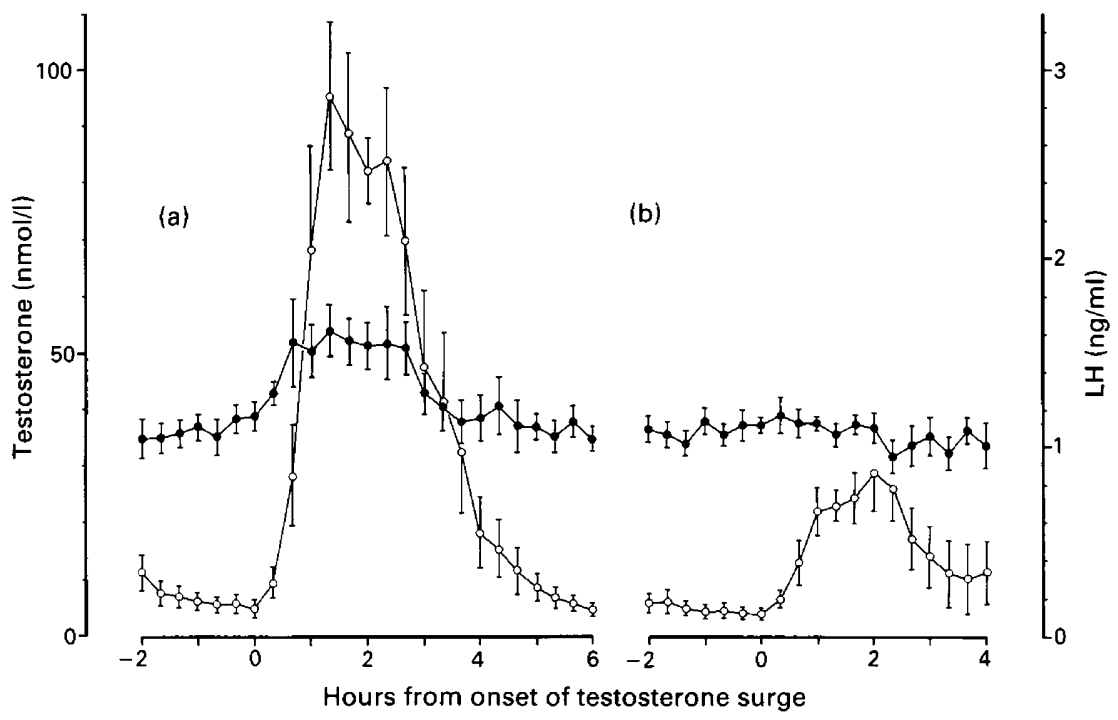

Fig. 3. Profiles of mean ( \pm s.e.m.) plasma LH (O) and testosterone $(O)$ concentrations normalized about the onset of (a) afternoon and (b) early morning testosterone surges for control fallow bucks during the pre-rut (March) and rut (April) periods ( $n=6$ observations per profile).

deer conforms to daylength, and the presence of the melatonin implant is merely additive, with plasma melatonin concentrations rising in response to the onset of darkness (Asher et al., 1988). The bucks in the present experiment would therefore still be presumably registering both day-night patterns in melatonin secretion and the natural photoperiodic changes. The implants, however, extended the concentrations of melatonin normally seen during darkness into the daylight hours. Previous workers using melatonin implants have concluded that the implants induce short-day effects in treated animals (Kennaway, 1988; Arendt et al., 1988; O'Callaghan et al., 1989), suggesting a strong duration element in the transduction of the melatonin signal of photoperiod. As sustained release of melatonin from subcutaneous implants can induce short-day effects in superior cervical-ganglionectomized rams, the mode of action is not simply due to blockade of the endogenous melatonin signal (Lincoln, 1988).

In an earlier study (Asher et al., 1989) we observed major changes in the dynamics of LH and testosterone secretion in entire bucks approaching the rut. The high-frequency pulsatility of LH and testosterone observed in February gave way to reductions in LH pulse rate, increased basal LH concentrations and massive fluctuations in plasma testosterone concentrations in March and April. The present study confirms this observation over longer (24-h) sampling periods. It further confirms the apparent synchrony among bucks in the episodic secretion of testosterone, indicating that such endocrine events reflect a circadian rhythm in testicular secretory activity. Such synchronous rhythms were also apparent in the February (rut) profiles of the melatonin-treated bucks, although the frequency of testosterone surges was greater than for the pre-rut and rut profiles of control bucks. Characteristically, the major testosterone surge occurred between early afternoon and dusk in the control and treated bucks, suggesting that entrainment is possibly via day:night patterns or daily activity patterns.

The episodic secretion of testosterone during the rut period was not manifest as discrete pulse episodes but rather as regular surges. These episodes occurred in the presence of high basal LH secretion but were only occasionally associated with a detectable LH pulse. Similar data have been reported for red deer stags (Lincoln \& Kay, 1979). The high-amplitude plasma testosterone surges occurring in the afternoon in sexually active males were associated with an overall increase in mean 
plasma LH values for the duration of the surge. However, this was not the case for the loweramplitude surges occurring in the early morning hours. This raises questions about the modulation of testosterone secretion during the period of peak sexual activity in male deer. It is suggestive of an endogenous rhythm that may be largely independent of pituitary control and contrasts quite markedly with the definitive cause-effect interaction of LH and testosterone secretion during the period of sexual development. Notwithstanding the observed patterns, it is entirely possible that LH assay sensitivity and the blood sampling frequency limit the ability to detect causative LH secretory events during the rut period. Elucidation of the actual physiological events may necessitate experimental manipulation of endogenous $\mathrm{LH}$ concentrations and subsequent monitoring of testosterone secretion.

We thank M. Langridge, O.C. Chitty and H. H. Humble, and other staff at the Ruakura Deer Unit, for technical assistance; Robyn McLaughlin and Karen Wentworth for hormonal analyses; D. Duganzich for statistical advice; and Dr L. D. Staples of Regulin Ltd, Australia, for supply of melatonin implants.

\section{References}

Arendt, J., Symons, A.M., English, J., Poulton, A.L. \& Tobler, I. (1988) How does melatonin control seasonal reproductive cycles? Reprod. Nutr. Develop. 28 (2B), 387-397.

Asher, G.W., Barrell, G.K. \& Peterson, A.J. (1986) Hormonal changes around oestrus of farmed fallow deer (Dama dama). J. Reprod. Fert. 78, 487-496.

Asher, G.W., Day, A.M. \& Barrell, G.K. (1987) Annual cycle of liveweight and reproductive changes of farmed male fallow deer (Dama dama) and the effect of daily oral administration of melatonin in summer on the attainment of seasonal fertility. J. Reprod. Fert. 79, 353-362.

Asher, G.W., Barrell, G.K., Adam, J.L. \& Staples, L.D. (1988) Effects of subcutaneous melatonin implants on reproductive seasonality of farmed fallow deer (Dama dama). J. Reprod. Fert. 84, 679-691.

Asher, G.W., Peterson, A.J. \& Bass, J.J. (1989) Seasonal pattern of $\mathrm{LH}$ and testosterone secretion in adult male fallow deer, Dama dama. J. Reprod. Fert. 85, 657665 .

Chapman, D.I. \& Chapman, N. (1975) Fallow Deer: Their History, Distribution and Biology. Terence Dalton Ltd, Lavenham, UK.

Karsch, F.J., Malpaux, B., Wayne, N.L. \& Robinson, J.E. (1988) Characteristics of the melatonin signal that provide the photoperiodic code for timing seasonal reproduction in the ewe. Reprod. Nutr. Develop. 28 (2B), 459472.

Kelly, R.W., McNatty, K.P., Moore, G.H., Ross, D. \& Gibb, M. (1982) Plasma concentrations of LH, prolactin, oestradiol and progesterone in female red deer (Cervus elaphus) during pregnancy. J. Reprod. Fert. $64,475-483$.
Kennaway, D.J. (1988) Short- and long-term effects of manipulation of the pineal/melatonin axis in ewes. Reprod. Nutr Develop. 28 (2B), 399-408.

Lincoln, G.A. (1988) Endogenous opioids and the control of $\mathrm{LH}$ secretion during the reproductive cycle in the ram induced by treatment with melatonin. Reprod. Nutr. Develop. 28, 527-539.

Lincoln, G.A. \& Kay, R.N.B. (1979) Effects of season on the secretion of LH and testosterone in intact and castrated red deer stags (Cervus elaphus). J. Reprod. Fert. 55, 75-80.

Lincoln, G.A. \& Ebling, F.J.P. (1985) Effect of constantrelease implants of melatonin on seasonal cycles in reproduction, prolactin secretion and moulting in rams. J. Reprod. Fert. 73, 241-253.

Merriam, G.R. \& Wachter, K.W. (1982) Algorithms for the study of episodic hormone secretion. Am. J. Physiol. 243, E310-E318.

O'Callaghan, D., Roche, J.F. \& Boland, M.P. (1989) What photoperiodic signal does a melatonin implant convey to ewes? Irish J. agric. Res. 28, 100-101.

Peterson, A.J., Fairclough, R.J. \& Smith, J.F. (1978) Radioimmunoassay of androstenedione and testosterone in cow plasma at the time of luteolysis and oestrus. J. Reprod. Fert. 52, 127-129.

Scaramuzzi, R.J., Caldwell, B.V. \& Moor, R.M. (1970) Radioimmunoassay of $\mathrm{LH}$ and estrogen during the estrous cycle of the ewe. Biol. Reprod. 3, 110-119.

Schnare, H. \& Fischer, K. (1987) Secondary sex characteristics and connected physiological values in male fallow deer (Dama dama) and their relationship to changes of the annual photoperiod: doubling the frequency. J. exp. Zool. 244, 463-471.

Received 14 July 1990 